\title{
Lack of cross-resistance between non-steroidal and steroidal aromatase inhibitors in breast cancer patients: the potential role of the adipokine leptin
}

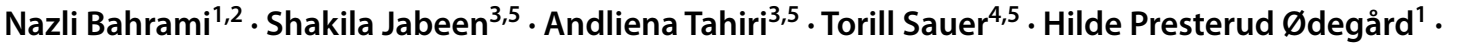 \\ Stephanie Beate Geisler ${ }^{1}$ • Berit Gravdehaug ${ }^{2}$ - Laurens Cornelus Reitsma ${ }^{2}$ Knut Selsås ${ }^{2}$ - Vessela Kristensen ${ }^{3,5}$. \\ Jürgen Geisler ${ }^{1,6}$ (iD
}

Received: 23 September 2020 / Accepted: 11 September 2021 / Published online: 23 September 2021

(c) The Author(s) 2021

\begin{abstract}
Purpose The aromatase inactivator exemestane may cause clinical disease stabilization following progression on nonsteroidal aromatase inhibitors like letrozole in patients with metastatic breast cancer, indicating that additional therapeutic effects, not necessarily related to estrogen-suppression, may be involved in this well-known "lack of cross-resistance".

Methods Postmenopausal women with ER positive, HER-2 negative, locally advanced breast cancer were enrolled in the NEOLETEXE-trial and randomized to sequential treatment starting with either letrozole (2.5 mg o.d.) or exemestane (25 mg o.d.) followed by the alternative aromatase inhibitor. Serum levels of 54 cytokines, including 12 adipokines were assessed using Luminex xMAP technology (multiple ELISA).

Results Serum levels of leptin were significantly decreased during treatment with exemestane $(p<0.001)$, regardless whether exemestane was given as first or second neoadjuvant therapy. In contrast, letrozole caused a non-significant increase in serum leptin levels in vivo.

Conclusions Our findings suggest an additional and direct effect of exemestane on CYP-19 (aromatase) synthesis presumably due to effects on the CYP19 promoter use that is not present during therapy with the non-steroidal aromatase inhibitor letrozole. Our findings provide new insights into the influence of clinically important aromatase inhibitors on cytokine levels in vivo that contribute to the understanding of the clinically observed lack of cross-resistance between non-steroidal and steroidal aromatase inhibitors in breast cancer patients.

Trial registration Registered on March 23rd 2015 in the National trial database of Norway (Registration number: REK-SØ-84-2015).
\end{abstract}

Keywords Breast cancer $\cdot$ Aromatase inhibitor $\cdot$ Letrozole $\cdot$ Exemestane $\cdot$ Adipokine $\cdot$ Leptin

\section{Abbreviations}

AIs Aromatase inhibitors

AP-1 Activator protein 1

CYP19 Cytochrome P-450 19 (aromatase)

Nazli Bahrami and Shakila Jabeen have contributed equally.

Jürgen Geisler

juergen.geisler@medisin.uio.no

1 Department of Oncology, Akershus University Hospital, Lørenskog, Norway

2 Department of Breast and Endocrine Surgery, Akershus University Hospital, Lørenskog, Norway

3 Department of Clinical Molecular Biology (EPIGEN), Akershus University Hospital, Lørenskog, Norway
ER Estrogen receptor

FSH Follicle-stimulating hormone

HER-2 Human epidermal growth factor receptor

IGF-I Insulin-like-growth factor I

INF Interferon

4 Department of Pathology, Akershus University Hospital, Lørenskog, Norway

5 Department of Cancer Genetics, Institute for Cancer Research, Oslo University Hospital, University of Oslo, Oslo, Norway

6 Institute of Clinical Medicine, University of Oslo, Oslo, Norway 


$\begin{array}{ll}\text { LH } & \text { Luteinizing hormone } \\ \text { IRS } & \text { Insulin receptor substrate } \\ \text { JAK } & \text { Janus tyrosine kinase } \\ \text { LABC } & \text { Locally advanced breast cancer } \\ \text { MAPK } & \text { Mitogen-activated protein kinase } \\ \text { MMPs } & \text { Matrix metalloproteinases } \\ \text { MRI } & \text { Magnetic resonance imaging } \\ \text { NET } & \text { Neoadjuvant endocrine therapy } \\ \text { PDGF } & \text { Platelet-derived growth factor } \\ \text { PR } & \text { Progesterone receptor } \\ \text { SOCS } & \text { Suppressor of cytokine signaling } \\ \text { STAT } & \text { Signal transducer and activator of transcription } \\ \text { TNF } & \text { Tumor necrosis factor } \\ \text { VEGF } & \text { Vascular endothelial growth factor }\end{array}$

\section{Introduction}

The third-generation aromatase inhibitors (AIs) (anastrozole, letrozole and exemestane) are widely used to treat estrogen receptor positive $(\mathrm{ER}+)$ breast cancer in postmenopausal patients in all stages of the disease [1-6].

Anastrozole and letrozole belong to the type-I class of non-steroidal aromatase inhibitors binding competitively to the P450 part of the aromatase enzyme. In contrast, the steroidal, type-II class aromatase inactivator exemestane binds irreversibly to the substrate binding pocket (active site) of the aromatase enzyme [7-9]. The fundamental biochemical differences between non-steroidal and steroidal aromatase inhibitors are from a clinical point of view of particular interest as a "lack of cross-resistance" has been documented in several clinical trials [10-16], providing the rationale for the use of exemestane following disease progression during treatment with a non-steroidal compound like letrozole [17]. However, the precise explanation for the observed lack of cross-resistance between steroidal and non-steroidal aromatase inhibitors is still unknown and it has been suggested that a detailed understanding of this clinical phenomenon may potentially provide a new strategy to treat hormonesensitive breast cancer $[18,19]$. To investigate the fundamental differences in the effects caused by non-steroidal AIs and steroidal AIs in vivo, we designed the NEOLETEXEtrial [20]. The present manuscript reports the results of a preplanned cytokine-substudy of the NEOLETEXE-trial.

Adipose inflammation is increasingly recognized as a crucial factor in breast cancer carcinogenesis and progression $[21,22]$. Typical consequences are hyperinsulinemia, elevated insulin-like growth factor I (IGF-I) levels, adipokine imbalances including leptin elevation as well as increased estrogen levels [21]. The adipokine leptin seems to play a pivotal role through binding to specific membrane receptors and inducing different signaling pathways, including the JAK/STAT, MAPK, IRS ${ }_{1}$ and $\mathrm{SOC}_{3}$ pathways [23].
Leptin is also involved in the regulation of body weight and is an important mediator of obesity as it controls food intake and energy balance by signals to the hypothalamus [24-26]. An excess of body fat mass increases the breast cancer risk, especially in postmenopausal women where estrogen production by adipose tissue through its own aromatase activity stimulates tumor progression [27]. Leptin is secreted by normal and malignant breast tissue and has been shown to enhance the expression of aromatase via promoter II and I.3 using an AP-1 motif [27]. A significant association between plasma sex hormones and plasma leptin levels has been reported [28, 29] and previous studies have shown that postmenopausal women with breast cancer have higher concentrations of plasma leptin [30, 31]. In a previous publication we could also show that plasma leptin levels are tightly correlated to the basic whole body aromatization in postmenopausal women [31].

In the present study, we evaluated the serum levels of 54 cytokines, including all 12 known adipokines, relative to given treatment with letrozole and exemestane in a neoadjuvant setting, aiming for a direct head-to-head comparison in vivo. We hypothesized that the different effects of letrozole and exemestane on the expression of crucial adipokines like leptin may play a key role in the mentioned lack of cross-resistance between type-I and type-II aromatase inhibitors. Importantly, our study was not primarily designed to compare the clinical effects on the breast cancer tumors as both drugs have been shown to cause comparable tumor shrinkage in the neoadjuvant setting in previous trials.

\section{Materials and methods}

\section{Trial design and patients}

The NEOLETEXE-study (Fig. 1) is a neoadjuvant, randomized, open-label, intra-patient, cross-over trial with the intention to study the effects of sequential aromatase inhibition by type-I aromatase inhibitor letrozole and type-II aromatase inactivator exemestane in vivo. The trial has been approved by the Regional Ethics Committee of SouthEast Norway (project number 2015/84) [20]. In this particular sub-study, a total of 39 postmenopausal women, all diagnosed with locally advanced, ER-positive and HER-2 negative primary cancer were included (Table 1). Locally advanced breast cancer (LABC) was defined as either T3-T4 and/or N2-3 primary breast cancer. However, patients with tumors above $4 \mathrm{~cm}$ but below $5 \mathrm{~cm}$ in diameter ("large T2-tumors") were also includable in accordance with the international trend to provide neoadjuvant therapies to these patients in clinical trials. We defined postmenopausal status as age above 55 years or age above 50 years and at least 
Fig. 1 Study design - the NEOLETEXE study

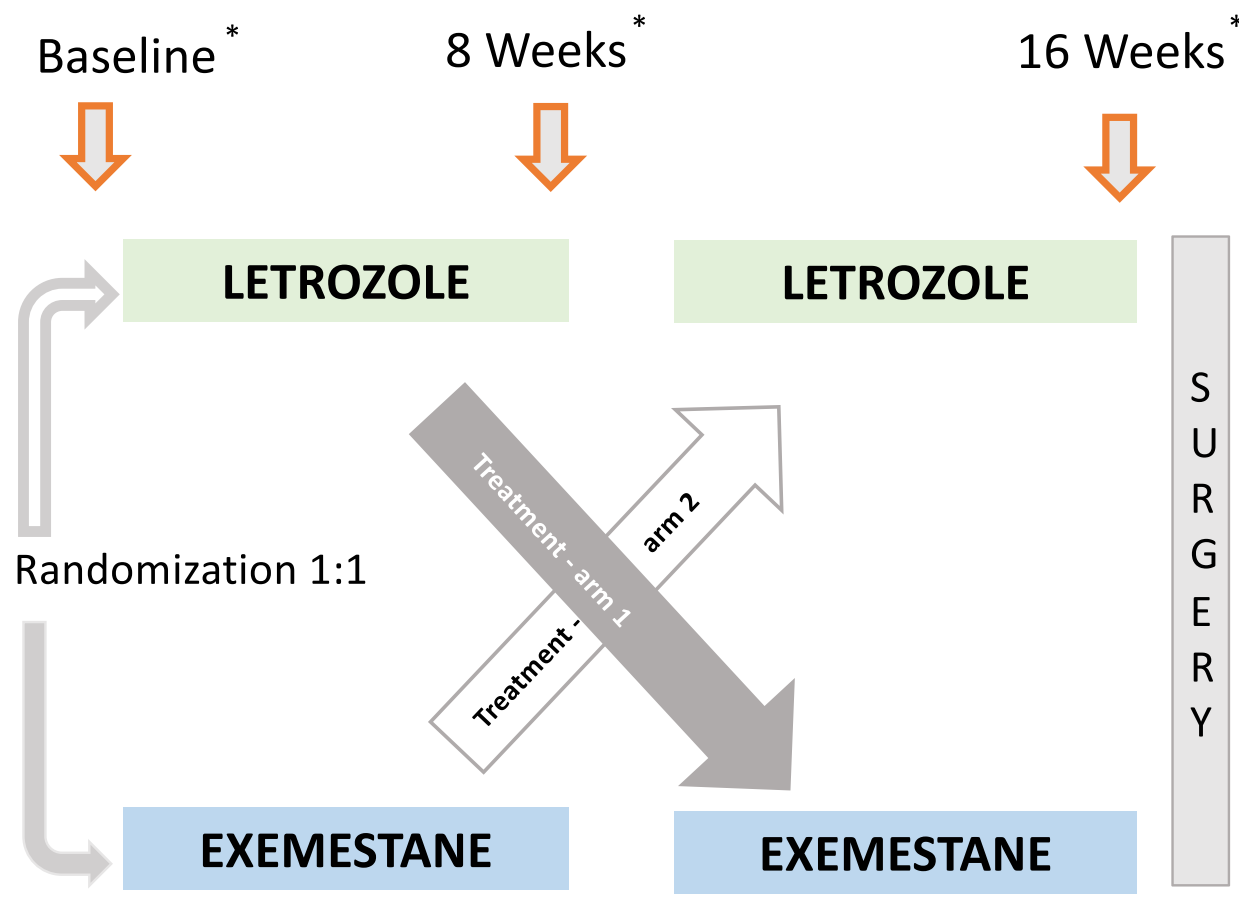

*Blood samples / tumor biopsies / clinical evaluations etc.

2 years of amenorrhea in addition to LH-, FSH- and plasma estradiol levels in the postmenopausal range.

Patients were randomized to neoadjuvant endocrine therapy (NET) by one of two treatment arms (Fig. 1).

\section{Treatment arm 1}

Letrozole (Femarß) $2.5 \mathrm{mg}$ o.d. for at least 8 weeks, followed by exemestane $25 \mathrm{mg}$ o.d. for another 8 weeks prior to surgery.

\section{Treatment arm 2}

Exemestane (Aromasin $®$ ) $25 \mathrm{mg}$ o.d. for at least 8 weeks, followed by letrozole $2.5 \mathrm{mg}$ o.d. for another 8 weeks prior to surgery.

Collection of blood samples, breast tumor biopsies, MRI evaluations and clinical examinations were performed at baseline (before initiation of any therapy), following at least 2 months on the first AI treatment (directly before switching to second treatment) and, finally, directly prior to surgery.

\section{Cytokine multiplex profiling}

In total 54 cytokines including all 12 adipokines, IL10 family cytokines, IL6 and its receptors, IFN, tumor necrosis factor (TNF) superfamily cytokines, growth factors, osteokines and selected matrix metalloproteinases (MMPs) were analyzed in serum samples obtained from 39 postmenopausal breast cancer patients treated according to the NEOLETEXE-protocol. Blood samples were obtained at three timepoints: at baseline and following at least 2 months and 4 months on therapy with the two individual aromatase inhibitors given in a randomized sequence as monotherapy. The multiplex profiling platform Luminex 200 was used for quantitative analysis of the cytokines. We used three commercially available cytokine panels from Bio-Rad and one panel from Millipore. Panels from Bio-Rad included: 37-plex Pro Human Inflammation Panel 1 (lot\# 64161726), Pro Human Adiponectin 1-plex Panel (lot \#10010747) and 15-plex including 10-plex Pro Diabetes Panel (lot \#64065098) plus five cytokines: IL6, IP10, VEGF, PDGFbeta and TNFalpha (standards lot\# 64103329). The interleukin 24 (IL-24) single plex panel was purchased from Millipore (lot\#HCYP4MMAG-64K-IL-24). Signal intensities of protein concentration for all cytokines were determined in a series of control standard dilutions to create standard curves as instructed by the manufacturers. The total serum protein level for each cytokine was assessed according to their locations on the standard curves using Bio-Plex Manager 6.0 (Bio-Rad). Data were exported to excel sheets for further analysis.

\section{Statistical analysis}

All analyses were performed after natural log transformation of the observed data using IBM SPSS Statistics 25 
Table 1 Patient characteristics

\begin{tabular}{|c|c|c|c|c|c|c|c|c|}
\hline Patient & Age & BMI & cTNM & Type & ER (\%) & PG & HER-2 & Treatment \\
\hline 1 & 66 & 28 & T4N1M0 & NST & $>50$ & Negative & Negative & LET-EXE \\
\hline 2 & 70 & 22 & T4N1M0 & NST & $>50$ & Negative & Negative & EXE-LET \\
\hline 3 & 76 & 24 & T3N1M1 & NST & $>50$ & Negative & Negative & LET-EXE \\
\hline 4 & 64 & 28 & T4N0M0 & ILC & $>50$ & Negative & Negative & EXE-LET \\
\hline 5 & 61 & 27 & T3N0M0 & NST & 100 & $>10 \%$ & Negative & LET-EXE \\
\hline 6 & 81 & 26 & T4N0M0 & ILC & 100 & $15 \%$ & Negative & EXE-LET \\
\hline 7 & 87 & 23 & T4N0M0 & NST & $>50$ & $>10 \%$ & Negative & LET-EXE \\
\hline 8 & 82 & 26 & T4N1M0 & NST & 100 & Negative & Negative & EXE-LET \\
\hline 9 & 73 & 28 & T4N0M0 & NST & 90-100 & $>90 \%$ & Negative & LET-EXE \\
\hline 10 & 80 & 27 & T4N0M0 & NST & $>50$ & $>10 \%$ & Negative & EXE-LET \\
\hline 11 & 87 & 28 & T4N0M0 & NST & $>50$ & $>90 \%$ & Negative & EXE-LET \\
\hline 12 & 78 & 31 & T4N0M0 & NST & $>50$ & Negative & Negative & LET-EXE \\
\hline 13 & 62 & 27 & T4N0M0 & NST & $>50$ & $>10 \%$ & Negative & EXE-LET \\
\hline 14 & 62 & 22 & T4N0M0 & ILC & $>50$ & $>10 \%$ & Negative & LET-EXE \\
\hline 15 & 84 & 29 & T3N1M0 & NST & $>50$ & $>10 \%$ & Negative & EXE-LET \\
\hline 16 & 83 & 30 & T4N0M0 & NST & 100 & $>50 \%$ & Negative & LET-EXE \\
\hline 17 & 62 & 25 & T4N1M0 & NST & $>50$ & $>10 \%$ & Negative & EXE-LET \\
\hline 18 & 85 & 23 & T4N0M0 & ILC & 100 & $100 \%$ & Negative & LET-EXE \\
\hline 19 & 77 & 24 & T4N0M0 & NST & 100 & $90 \%$ & Negative & EXE-LET \\
\hline 20 & 71 & 28 & T4N0M0 & NST & $>50$ & $>10 \%$ & Negative & LET-EXE \\
\hline 21 & 76 & 30 & T3N1M0 & ILC & $>50$ & Negative & Negative & EXE-LET \\
\hline 22 & 67 & 36 & T4N0M0 & NST & $>50$ & $>10 \%$ & Negative & LET-EXE \\
\hline 23 & 83 & 31 & T4N0M0 & IAC & $>50$ & $>10 \%$ & Negative & EXE-LET \\
\hline 24 & 89 & 24 & T4N0M0 & NST & $>50$ & $>10 \%$ & Negative & LET-EXE \\
\hline 25 & 82 & 25 & T3N0M0 & NST & $>50$ & $>10 \%$ & Negative & EXE-LET \\
\hline 26 & 83 & 35 & T4N0M0 & NST & $>50$ & $>10 \%$ & Negative & LET-EXE \\
\hline 27 & 70 & 28 & T4N1M1 & NST & 100 & $>50 \%$ & Negative & EXE-LET \\
\hline 28 & 71 & 30 & T4N0M0 & NST & 100 & $>50 \%$ & Negative & LET-EXE \\
\hline 29 & 73 & 31 & T4N0M0 & ILC & 100 & $>50 \%$ & Negative & EXE-LET \\
\hline 30 & 67 & 28 & T3N0M0 & SNEC & 100 & $100 \%$ & Negative & EXE-LET \\
\hline 31 & 74 & 35 & T3N0M0 & ILC & 100 & $100 \%$ & Negative & LET-EXE \\
\hline 32 & 78 & 25 & T4N1M0 & ILC & $>50$ & $>10 \%$ & Negative & EXE-LET \\
\hline 33 & 80 & 18 & T4N1M0 & SNEC & 100 & $100 \%$ & Negative & LET-EXE \\
\hline 34 & 80 & 21 & T4N0M0 & ILC & 100 & $100 \%$ & Negative & EXE-LET \\
\hline 35 & 78 & 27 & T3N0M0 & ILC & 100 & $>50 \%$ & Negative & LET-EXE \\
\hline 36 & 73 & 34 & T4N0M0 & NST & $>90$ & $>10 \%$ & Negative & EXE-LET \\
\hline 37 & 79 & 22 & T4N0M0 & ILC & $>50$ & Negative & Negative & LET-EXE \\
\hline 38 & 79 & 32 & T4N1M0 & ILC & 100 & $20-30 \%$ & Negative & EXE-LET \\
\hline 39 & 70 & 32 & T4N0M0 & NST & $>50$ & $>10 \%$ & Negative & LET-EXE \\
\hline
\end{tabular}

$B M I$ Body Mass Index, $c T N M$ clinical and radiological examination of tumors size (T), lymph node status $(\mathrm{N})$ and distant metastases (M), ER estrogen receptor, EXE-LET treatment sequence (neoadjuvant): exemestane followed by letrozole, $H E R-2$ human epidermal growth factor receptor 2, ILC invasive lobular carcinoma, IAC invasive apocrine carcinoma, LET-EXE treatment sequence: letrozole followed by exemestane (neoadjuvant), NST invasive carcinoma of no special type (historical term: invasive ductal carcinoma), $P G R$ progesterone receptor, $S N E C$ solid neuroendocrine carcinoma

and Excel 2016. Cytokine levels were analyzed in relation to categorical clinical parameters using ANOVA, Mann-Whitney-U (MWU), Kruskal-Wallis and $t$-tests. Unless otherwise stated, results were considered statistically significant, if the two-sided $p$-value was $<0.05$.
The cytokine correlation analysis was performed for pretreatment (baseline) log-transformed serum levels using Spearman correlations. Visualization of all finding was performed using either IBM SPSS Statistics 25's graphic elements or by use of Excel 2016. 


\section{Results}

We performed a serum level variation analysis for 54 cytokines from samples collected from 39 postmenopausal patients with locally advanced, ER positive, HER-2 negative breast cancer. Cytokine serum levels were measured using multiplex array system Luminex xMap and observed values were $\log$ normalized.

The log-transformed cytokine levels for all patients and the influence of treatment with letrozole and exemestane, respectively (given as differences to baseline values) are summarized in Table 2. Statistical analyses were performed using normalized serum levels values of the cytokines against clinical parameters and observations. The overall results of our findings illustrated in groups or families of cytokines which are put together according to their common function, origin, or both are given in Table 2. Spearman correlations were calculated between all adipokine baseline values as summarized in Fig. 2 . The correlations between adipokines are also given for the individual treatment arms over time in Supplementary Fig. 1.

Importantly, serum levels of leptin were found to be significantly decreased during treatment with exemestane compared to treatment with letrozole $(p<0.001)$, regardless whether exemestane was given as first or second therapy (Fig. 3). Our analysis also showed that treatment with letrozole slightly increased serum leptin levels without reaching the level of statistical significance. The leptin baseline levels showed a strong correlation to the body mass index (BMI) of the patients (rho $=0.7, p=0.001)$ as expected. The correlations between BMI and leptin levels at baseline and over time are summarized in Fig. 4. All in all, BMI and plasma leptin levels were highly correlated throughout both treatment arms. Concerning the other adipokines, we also observed a trend towards a reduction of serum levels of adiponectin during treatment with exemestane, however, without reaching the level of statistical significance. No significant changes in serum levels of any other adipokines were registered during treatment with aromatase inhibitors.

To further investigate the relationship between leptin serum levels, leptin gene expression in tumor tissue and CYP19 (aromatase) expression in corresponding tumor specimens, we calculated the correlations between these parameters using whole genome sequencing data that were available for these patients. The findings are summarized in Fig. 5. Briefly, our results suggest a strong suppression of CYP19 expression in the tumor tissue during treatment with exemestane even in women with elevated leptin levels (Fig. 5b). In contrast, increasing leptin serum concentrations were found to associated with increasing CYP19 expression during therapy with letrozole (Fig. 5a).
In addition to the already mentioned disturbances in the adipokine levels, we observed that some cytokines belonging to the TNF superfamily were found to be significantly $(p<0.01)$ decreased during letrozole therapy while increased during exemestane treatment. These included TNF alpha, TNF Receptor Superfamily Member 8 (TNFRSF8) or sCD30, and TNF Superfamily Member 13B (TNFS13B/ BAFF). The findings are summarized in Supplementary Fig. 2. Among all studied members of the IL-10 family of cytokines, we found only IL-11 to be significantly increased during letrozole therapy.

Among the other "regular" cytokines, we found IFN-beta, IL-12(p40) and VEGF to be significantly influenced by the aromatase inhibitors used in our trial (Table 2). Treatment with either letrozole or exemestane did not cause significant changes in all other cytokines measured in this study (sCD163, Chitinase 3-like 1, gp130, IFN-alpha2, IFNgamma, IL-2, sIL-6Ralpha, IL12(p70), IL32, IL34, IL35, IP10, PDGF-bb, osteocalcin, osteopontin, pentraxin-3, TSLP, IL-24).

The progesterone receptor (PR) status varied among patients participating in this study as expected for this subgroup of patients (Table 1). Interestingly, one member of the IL-10 cytokine family, interleukin 19 (IL-19), showed significant variations in serum levels relative to PR status. Thus, patients with PR negative breast cancer had significantly higher levels of IL-19 compared to patients with PR positive breast cancer $(p<0.01)$. The findings concerning relations between the PR tumor status and cytokine levels are summarized in Fig. 6.

Finally, we were also able to investigate the influence of letrozole and exemestane on MMPs and found significant differences $(p<0.01)$ comparing the levels of MMP1 and MMP3 while on treatment with the two AIs (summarized in: Table 2).

\section{Discussion}

While aromatase inhibitors are widely established as standard of care in all phases of ER positive breast cancer variants in postmenopausal women, several important questions are still unanswered concerning their basic mechanisms of action in vivo. Thus, a lack of crossresistance between non-steroidal aromatase inhibitors (like letrozole) and steroidal aromatase inactivators (like exemestane) has been well-documented during treatment of metastatic breast cancer [10, 12-16, 19, 32]. This phenomenon has caused the establishment of exemestane therapy, either as monotherapy or in concert with mTORinhibitors like everolimus, following progression on nonsteroidal AIs (letrozole/anastrozole) in the recommended treatment guidelines in many countries worldwide. To 


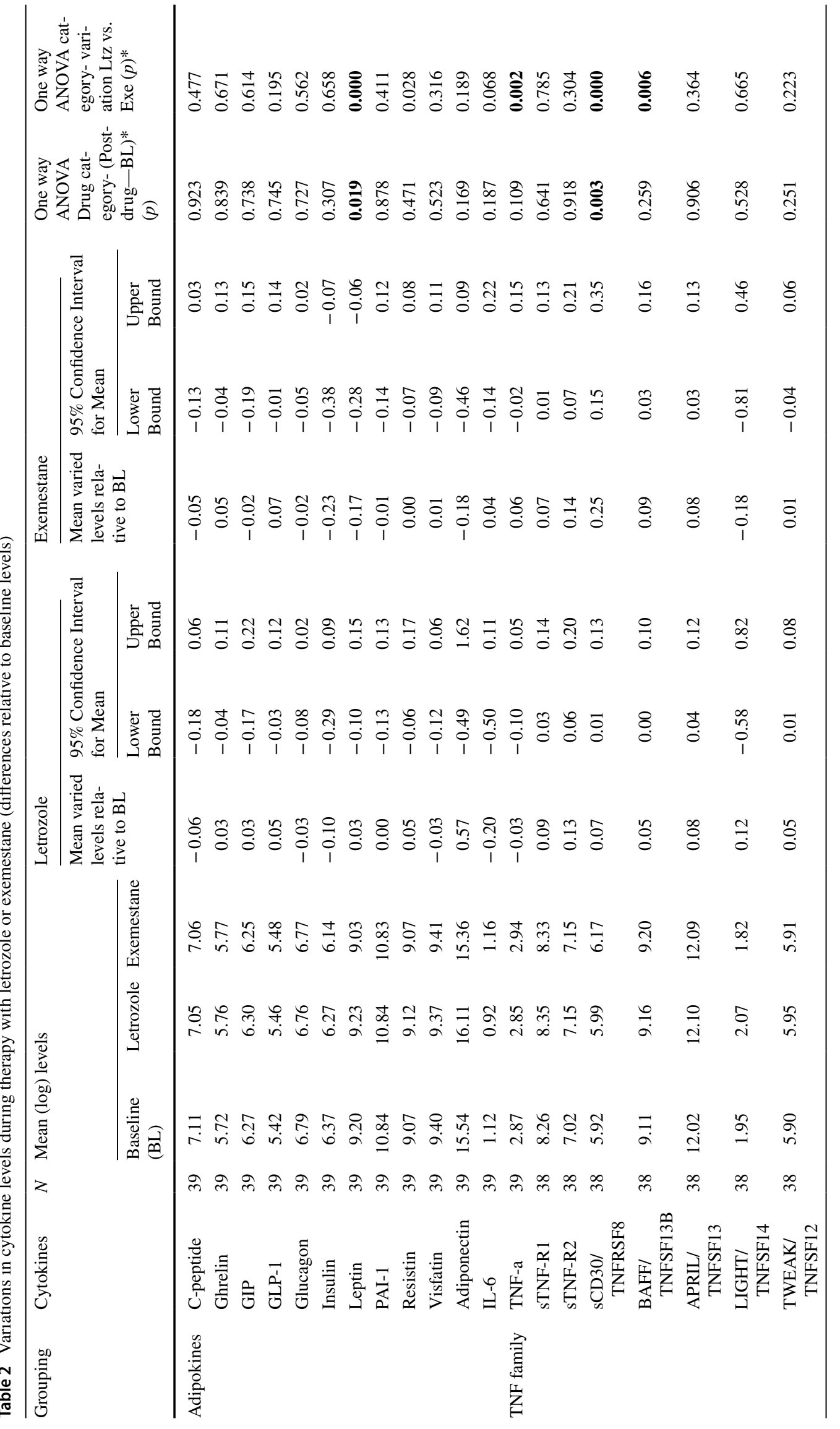




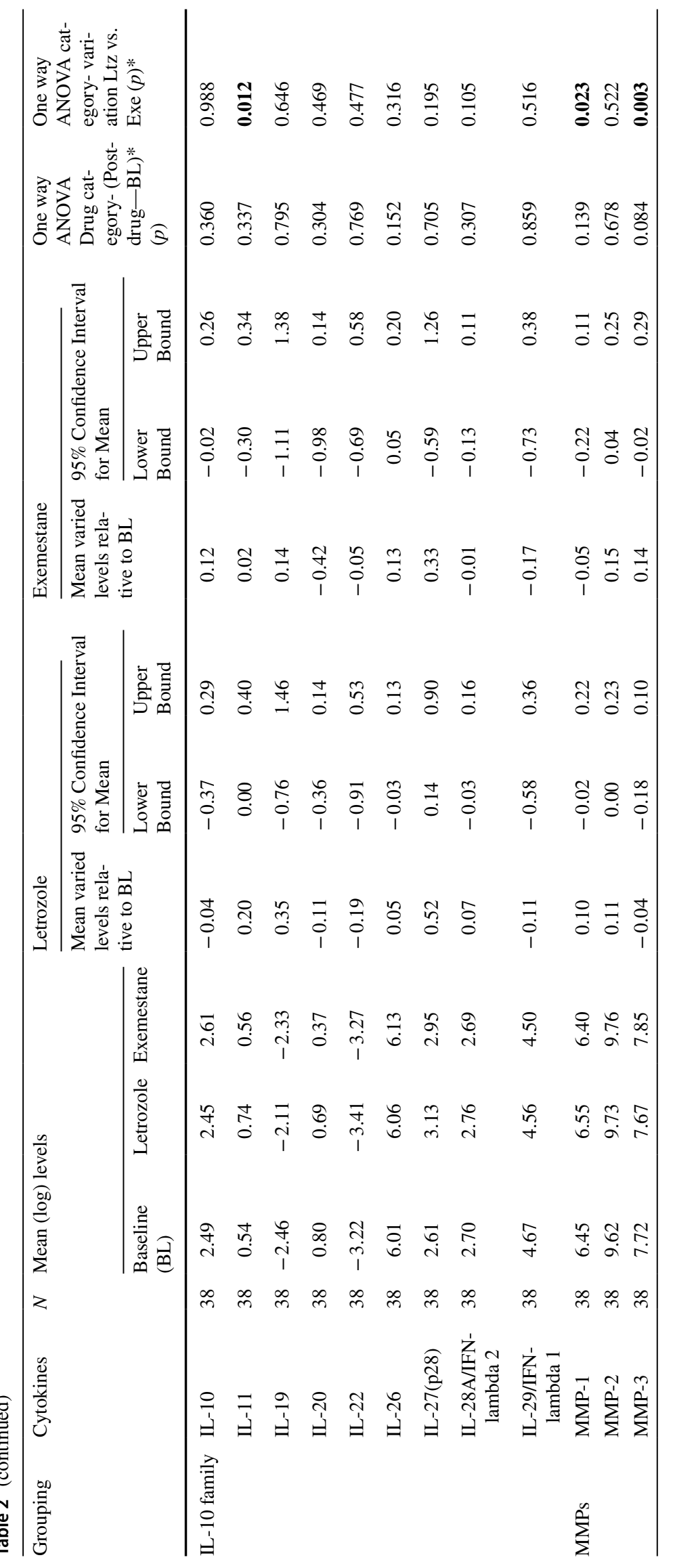




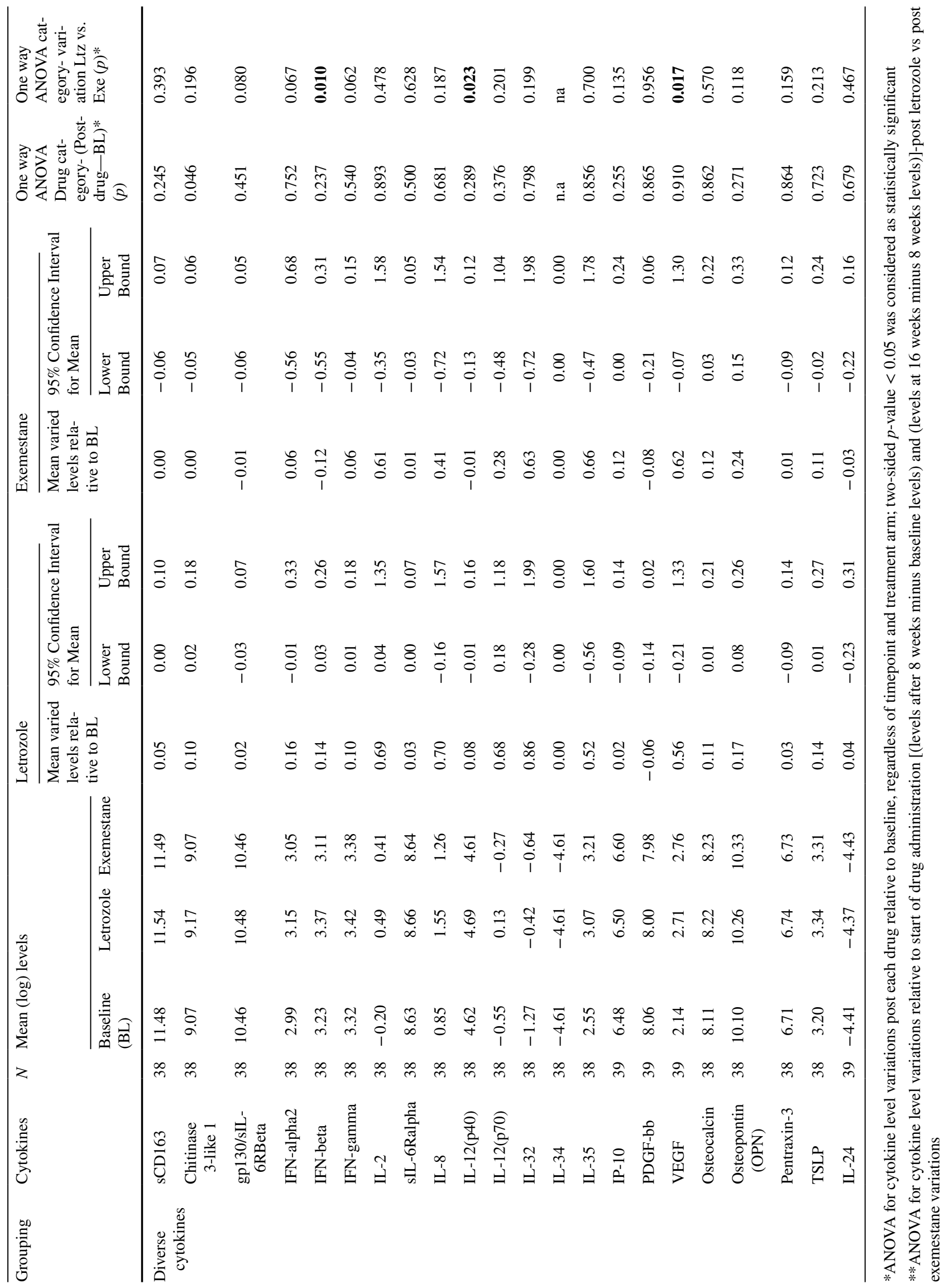


Fig. 2 Spearman correlations between baseline serum levels of adipokines. Spearman correlations between serum levels of 12 adipokines $(n=39$, timepoint: baseline) are shown by correlation dot plots, as well as by correlation coefficient values (rho) with significance $(p)$ values. Significant $p$ values are highlighted bold
Fig. 3 Influence of treatment with letrozole and exemestane on serum adipokine levels. Bar plot representing median log serum levels difference ( $y$-axis) of 12 adipokines (x-axis) in breast cancer patients $(n=39)$, relative to neoadjuvant drug type and therapy time-point (color categories). Error bars represent $95 \%$ confidence interval
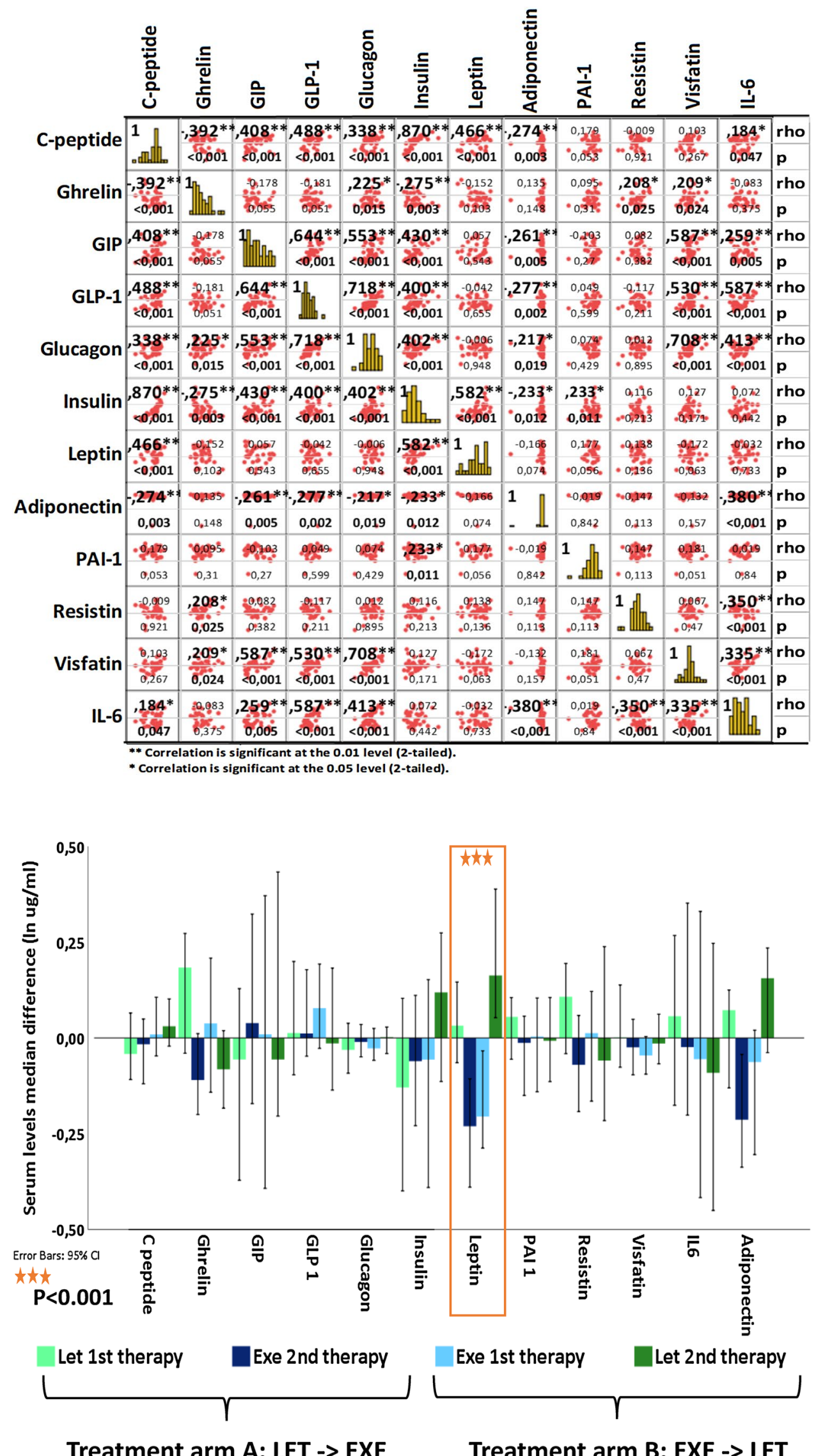

Treatment arm A: LET -> EXE Treatment arm B: EXE -> LET 

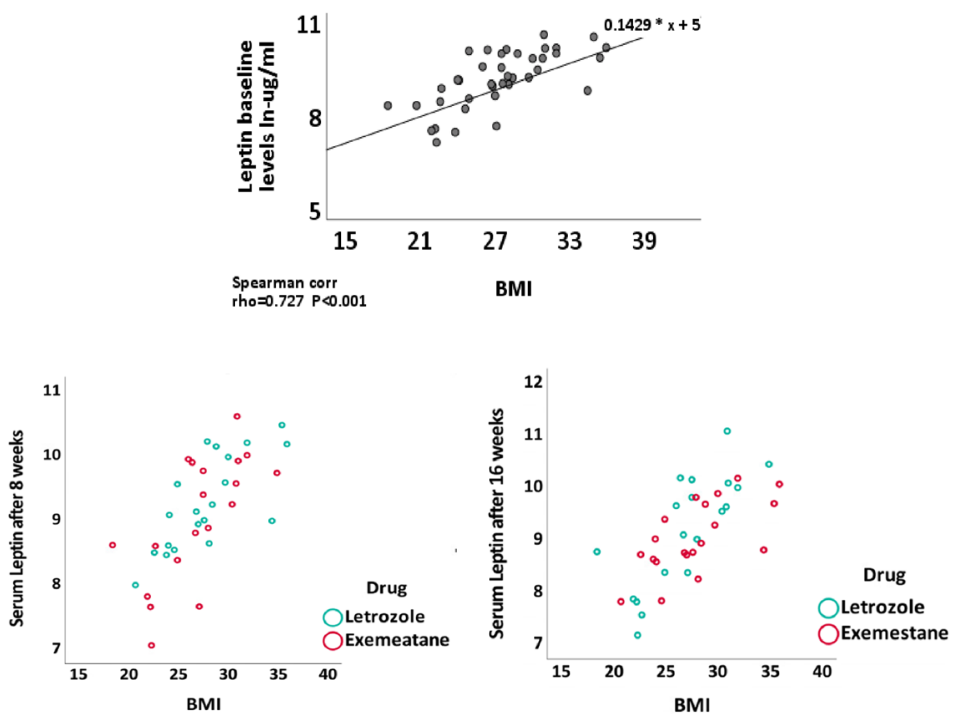

Spearman's Correlations: BMI to serum Leptin levels

\begin{tabular}{|c|c|c|}
\hline & & BMI \\
\hline \multirow[t]{3}{*}{ Leptin levels baseline } & Correlation Coefficient &, $727 * *$ \\
\hline & Sig. (2-tailed) & 0 \\
\hline & $\mathrm{N}$ & 39 \\
\hline \multicolumn{3}{|l|}{ Leptin levels on first Al } \\
\hline \multirow[t]{3}{*}{ Arm 1: Letrozole } & Correlation Coefficient &, $774 * *$ \\
\hline & Sig. (2-tailed) & 0 \\
\hline & $\mathrm{N}$ & 20 \\
\hline \multirow[t]{3}{*}{ Arm 2: Exemestane } & Correlation Coefficient & ,738** \\
\hline & Sig. (2-tailed) & 0 \\
\hline & $\mathrm{N}$ & 19 \\
\hline
\end{tabular}

Leptin levels on second AI

Arm 1: Exemestane

$\begin{array}{ll}\text { Correlation Coefficient } & , 713^{* *} \\ \text { Sig. (2-tailed) } & 0 \\ \text { N } & 20 \\ \text { Correlation Coefficient } & , 698^{* *} \\ \text { Sig. (2-tailed) } & 0,001 \\ \text { N } & 19\end{array}$

** Correlation is significant at the 0.01 level (2-tailed).

Fig. 4 Correlation between plasma leptin levels (baseline) and body mass index (BMI). Dot plot to illustrate Spearman correlation between BMI (x-axis) and serum levels of leptin (y-axis) in breast cancer patients

Fig. 5 Correlation between CYP19 (aromatase) expression and leptin blood levels as well as leptin gene expression. The correlation between leptin levels in serum and CYP19 (aromatase) expression in tumor tissue is given during therapy with letrozole (a) and exemestane (b). In addition, the correlation between the leptin gene (LEP) expression in tumor tissue and CYP19 (aromatase) expression in the same tumor specimens in given while on treatment with letrozole (c) and exemestane (d)
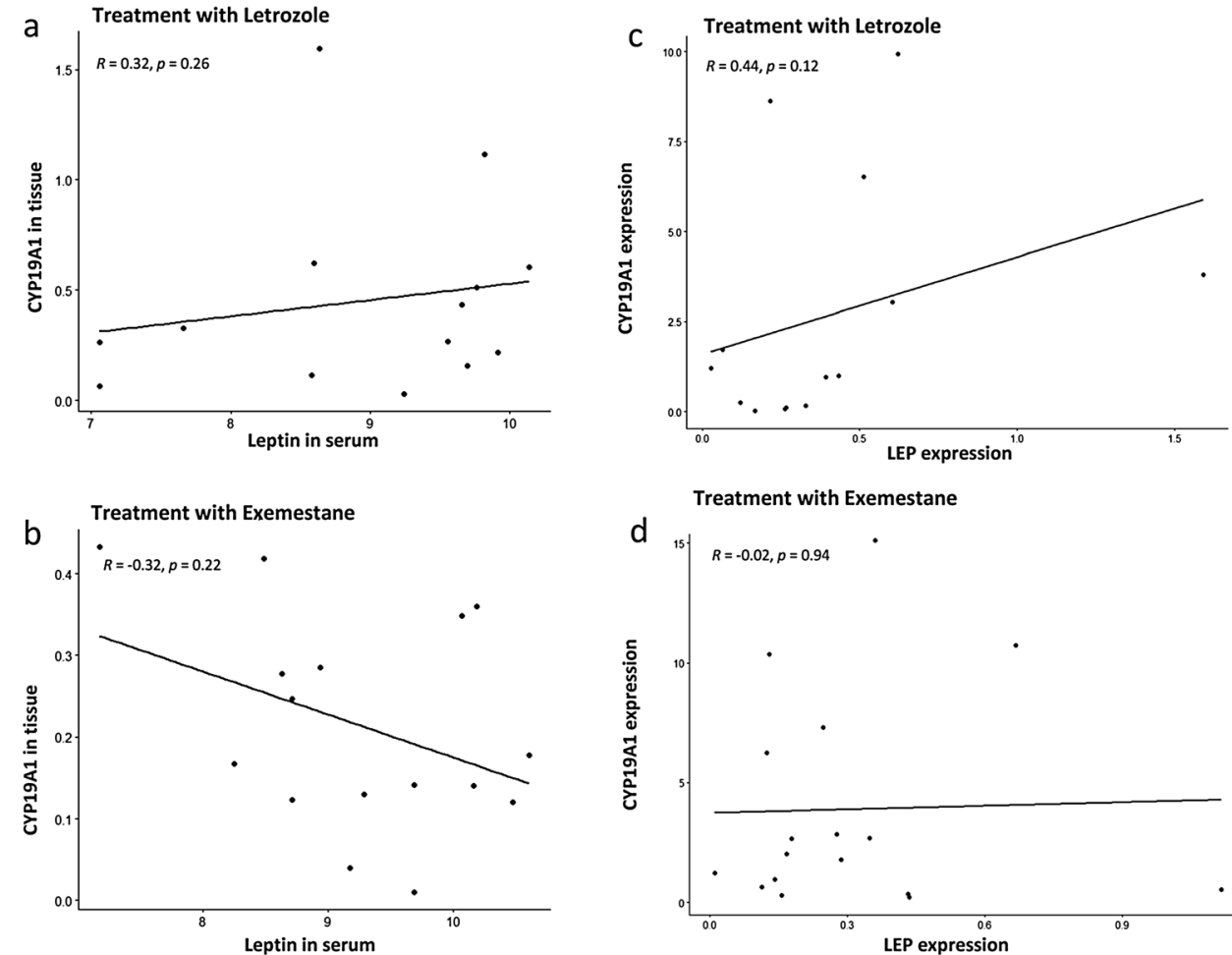

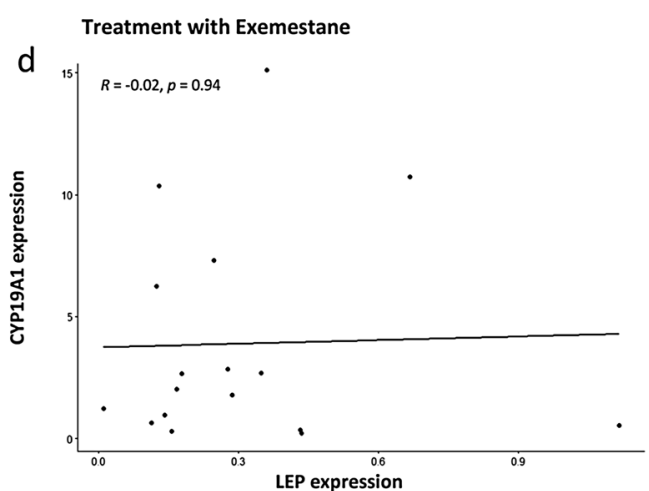

explore the potential mechanisms behind this important clinical observation, probably based on a fundamental, although not understood difference between the two major classes of AIs, we conducted the NEOLETEXE-trial at our institution. The study allows a direct head-to-head comparison of two of the most widely used aromatase disrupting agents, letrozole and exemestane. The results of a pre-planned substudy focusing on the influence of AI therapy on cytokines in general and adipokines in particular are given here. 
Fig. 6 Correlation between PR expression in breast cancer tissue specimens and selected cytokine levels. The serum levels of IL19 were found to be significantly higher $(p<0.01)$ in the samples obtained from patients harboring a progesterone receptor $(\mathrm{PR})$ negative tumor $(n=6)$ compared to patients with PR positive tumors $(n=32)$
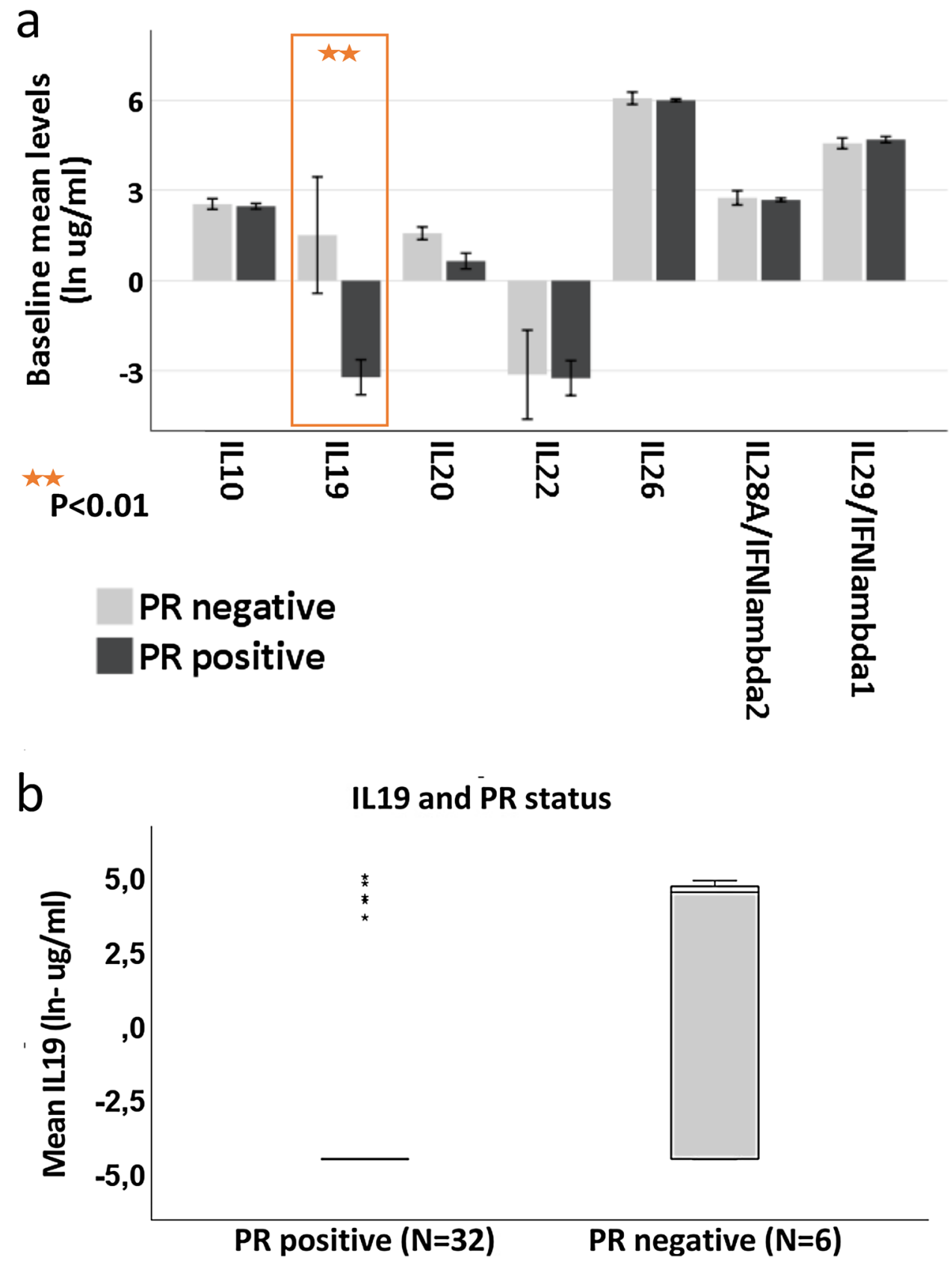

Most interestingly, we present here evidence for a strong negative effect of exemestane therapy on serum leptin levels that is strikingly contrasted by the absence of this effect during letrozole therapy when given to the same patients in sequence (Fig. 3). This finding was not at all depending on the sequence of drugs as it could be shown in both treatment arms independent whether exemestane was given as the first of second treatment in the neoadjuvant setting. While the regulation of leptin levels by steroids is still a controversial point [33], androgens have been suggested to decrease plasma leptin levels, while estrogens are believed to increase leptin levels in vivo [34-38]. Thus, one possible explanation for the observed decrease of plasma leptin levels during monotherapy with exemestane seen in our study may be due to the androgenic effects of exemestane and its major metabolite 17-hydroxy-exemestane [39]. Estrogen suppression alone did not decrease leptin levels in vivo as documented by a modest increase of leptin serum concentrations during monotherapy with the extremely potent aromatase inhibitor letrozole in our study. In contrast to the steroidal compound exemestane, letrozole belongs to the pharmacological group of triazoles and does not exert androgen effects in vivo. 
Our results indicate in fact a dual mode of action of exemestane in vivo. First, exemestane is working as a classical steroidal aromatase inactivator, causing metabolism of an aromatase molecule following binding of exemestane [4]. This reaction is also called "suicide-binding" in the literature [40]. In addition, our results presented here suggest an additional effect on aromatase expression due to the negative effect on leptin levels. Leptin has been shown to enhance aromatase expression via AP-1 in the MCF-7 cell line [27]. As a consequence, exemestane, in addition to be a classical aromatase inactivator, probably downregulates aromatase synthesis directly by suppression of leptin effects on promoter II and I.3 of the CYP19 gene. This additional effect of exemestane on the CYP19 promoter level is not present during therapy with letrozole, according to our findings presented here and may, at least partly, explain why exemestane may cause clinical responses in breast cancer patients who experience disease progression while on treatment with a non-steroidal aromatase inhibitor. We also investigated the correlation between leptin serum levels and leptin gene expression and CYP19 (aromatase) gene expression in corresponding tumor tissue specimens using whole genome sequencing (WGS) data. Briefly, our findings suggest a strong suppression of CYP19 gene expression in the tumor tissue during treatment with exemestane even in women with elevated leptin levels (Fig. 5b). In contrast, increasing leptin serum levels were found to be associated with increasing CYP19 expression during letrozole therapy.

Moreover, it has been shown by Catalano et al. [41] that leptin is able to induce a functional activation of ER alpha in MCF-7 cells via ERK1/ERK2 signaling. Thus, additional beneficial effects of leptin suppression by exemestane, not related to CYP19 regulation, cannot be entirely ruled out and may contribute to the reported clinical effects of exemestane following non-steroidal AIs.

Treatment with exemestane also caused a trend towards a (non-significant) suppression of serum adiponectin not observed during letrozole therapy. Adiponectin is produced by metabolically active white adipose tissue and inversely associated with adiposity. Adiponectin is believed to reduce the risk and the progression of breast cancer via its antiproliferative and possibly pro-apoptotic effects on breast cancer cells $[42,43]$. No other adipokines were considerably affected by treatment of exemestane or letrozole in this trial.

Our cytokine panels allowed us also to investigate the potential effects of letrozole and exemestane on selected members of the Tumor Necrosis Factor (TNF) superfamily. While all members of the TNF superfamily, consisting of 19 ligands and 29 receptors [44], have been suggested to be involved in a variety of cellular events including proliferation, differentiation and apoptosis, the B-cell activating factor of TNF family (BAFF) has recently gained extra attention due to its major role in regulating the tumor microenvironment including induction of apoptosis [45, 46]. In the present study we found SCD30/TNFRSF8 to be significantly increased during exemestane therapy $(p<0.003)$ while it was not modified by letrozole. Thus, our findings indicate distinct influences of different aromatase inhibitors on key regulators of inflammation and immunity in human breast cancer that deserve further investigation.

The patients enrolled in the NEOLETEXE-trial were typical luminal-A breast cancer patients with highly ER positive breast tumors with co-expression of PR in 31 of 39 individual cases. However, a sub-population with ER positive/PR negative tumors in our trial $(n=8)$ gave us the opportunity to study cytokine profiles in these two subgroups of patients. Although the patient numbers are actually small, we found significantly elevated IL-19 levels in patients with ER positive / PR negative BC when compared to ER pos./PR positive cases $(p<0.01)$. Interleukin 19 is a cytokine belonging to the IL-10 family with multiple roles in immune regulation [47, 48]. In breast cancer, interleukin 19 seems to play an especially important role in disease progression [49]. Hsing et al. recently showed that upregulated IL-19 is associated with poor clinical outcome in BC patients [50]. It is wellknown that loss of $\mathrm{PR}$ is indicating a worse prognosis in $\mathrm{BC}$ patients compared to $\mathrm{PR}$ positive cases, in general. The precise link between PR negativity and elevated IL-19 levels is currently unknown and will be investigated in follow-up studies.

Finally, we studied the effects of neoadjuvant letrozole and exemestane on metalloproteinases (MMPs). Breast cancer cells may release metalloproteinases to degrade matrix macromolecules, allowing the invasion of tissue barriers, blood vessels and lymph channel walls [51-54]. In our study, we were able to study the effects of AI therapy on three pivotal metalloproteinases simultaneously: MMP1 (collagenase-1), MMP2 (gelatinase-A) and MMP3 (stromelysin-1). We found a significant suppression of MMP1 during exemestane therapy when compared to letrozole $(p=0.023)$ and a significant suppression of MMP3 during therapy with letrozole $(p=0.003)$ when compared to exemestane, while the findings for MMP2 were not significantly different between the two AIs. Our findings are contrasting findings made by others, however obtained in vitro, showing that letrozole may decrease MMP2 levels [55]. Thus, aromatase inhibitors may have additional positive treatment effects on metalloproteinases by decreasing their levels in vivo as indicated here. These findings have to be confirmed in larger cohorts in the future.

In conclusion, treatment with exemestane significantly lowered serum leptin levels in breast cancer patients while letrozole did not. Our findings suggest a dual mode of action for exemestane, downregulating CYP-19 (aromatase) expression in the presence of high leptin levels probably due to effects on the CYP19 gene promoter involvement in 
addition to the well-known effects as a classical aromatase inactivator. The important role of leptin in breast cancer carcinogenesis and progression may influence the choice of aromatase inhibitors based on their distinct influence on adipokines like leptin in vivo. All in all, our results suggest a potential role for exemestane, especially in obese postmenopausal women who are typically harboring elevated leptin levels.

Supplementary Information The online version contains supplementary material available at https://doi.org/10.1007/s10549-021-06399-x.

Acknowledgements We would like to thank our study nurses Christin Johansen, Marie Loeng, Unn-Cathrin Buvarp and Annika Lorentzen who helped us to collect all blood and tissue samples during the NEOLETEXE-trial and all breast cancer patients who made this trial possible.

Author contributions JG contributed to the study conception, methodology, formal administration, data analysis, funding and supervision. NB, SJ, AT, TS, HPØ, SBG, BG, LCR, KS and VK contributed to the study methodology, investigation, project administration and formal analysis. All authors contributed to the writing of the manuscript and read and approved the final version.

Funding Open access funding provided by Akershus University Hospital (AHUS). This study is an investigator-initiated study without any support from the pharmaceutical industry. The authors want to thank the administration of the South-Eastern health region of Norway for a scientific Grant (No. 2017033) allowing this work to be performed as a part of the Ph.D. thesis of N.B. Additional funding by Bodil and Magne's Cancer Research Fund, Oslo, Norway, is highly appreciated.

Data availability Any requests for additional data or supporting material will be considered for qualified external researchers who provide a methodologically sound proposal. Proposals should be directed to the corresponding author in the first instance.

Code availability Not applicable.

\section{Declarations}

Conflict of interest JG has served on scientific advisory boards for AstraZeneca, Daiichi Sankyo, Eli Lilly, Novartis, Pierre Fabre, Pfizer and Roche. All other authors declare that they have no competing interests.

Ethical approval The research protocol was evaluated and approved by the Regional Ethics Committee of South-East Norway (project number 2015-84). The biobank for the NEOLETEXE-trial was approved by the Regional Ethics Committee in Oslo, Norway and located and administered at the Akershus University Hospital, Lørenskog, Norway.

Informed consent All patients gave their written informed consent prior to participation in the trial.

Open Access This article is licensed under a Creative Commons Attribution 4.0 International License, which permits use, sharing, adaptation, distribution and reproduction in any medium or format, as long as you give appropriate credit to the original author(s) and the source, provide a link to the Creative Commons licence, and indicate if changes were made. The images or other third party material in this article are included in the article's Creative Commons licence, unless indicated otherwise in a credit line to the material. If material is not included in the article's Creative Commons licence and your intended use is not permitted by statutory regulation or exceeds the permitted use, you will need to obtain permission directly from the copyright holder. To view a copy of this licence, visit http://creativecommons.org/licenses/by/4.0/.

\section{References}

1. Geisler J, Detre S, Berntsen H, Ottestad L, Lindtjorn B, Dowsett M, Einstein Lonning P (2001) Influence of neoadjuvant anastrozole (Arimidex) on intratumoral estrogen levels and proliferation markers in patients with locally advanced breast cancer. Clin Cancer Res 7(5):1230-1236

2. Geisler J, Haynes B, Anker G, Dowsett M, Lonning PE (2002) Influence of letrozole and anastrozole on total body aromatization and plasma estrogen levels in postmenopausal breast cancer patients evaluated in a randomized, cross-over study. J Clin Oncol 20(3):751-757. https://doi.org/10.1200/JCO.2002.20.3. 751

3. Geisler J, Helle H, Ekse D, Duong NK, Evans DB, Nordbo Y, Aas T, Lonning PE (2008) Letrozole is superior to anastrozole in suppressing breast cancer tissue and plasma estrogen levels. Clin Cancer Res 14(19):6330-6335. https://doi.org/10.1158/10780432.CCR-07-5221

4. Geisler J, King N, Anker G, Ornati G, Di Salle E, Lonning PE, Dowsett M (1998) In vivo inhibition of aromatization by exemestane, a novel irreversible aromatase inhibitor, in postmenopausal breast cancer patients. Clin Cancer Res 4(9):2089-2093

5. Geisler J, King N, Dowsett M, Ottestad L, Lundgren S, Walton P, Kormeset PO, Lonning PE (1996) Influence of anastrozole (Arimidex), a selective, non-steroidal aromatase inhibitor, on in vivo aromatisation and plasma oestrogen levels in postmenopausal women with breast cancer. Br J Cancer 74(8):1286-1291

6. Geisler J, Lonning PE (2005) Aromatase inhibition: translation into a successful therapeutic approach. Clin Cancer Res 11(8):2809-2821. https://doi.org/10.1158/1078-0432. CCR-04-2187

7. Cole PA, Robinson CH (1990) Mechanism and inhibition of cytochrome P-450 aromatase. J Med Chem 33(11):2933-2942. https://doi.org/10.1021/jm00173a001

8. di Salle E, Ornati G, Giudici D, Lassus M, Evans TR, Coombes RC (1992) Exemestane (FCE 24304), a new steroidal aromatase inhibitor. J Steroid Biochem Mol Biol 43(1-3):137-143. https:// doi.org/10.1016/0960-0760(92)90198-r

9. Lonning PE (2004) Aromatase inhibitors in breast cancer. Endocr Relat Cancer 11(2):179-189. https://doi.org/10.1677/erc.0.01101 79

10. Lonning PE, Bajetta E, Murray R, Tubiana-Hulin M, Eisenberg PD, Mickiewicz E, Celio L, Pitt P, Mita M, Aaronson NK, Fowst C, Arkhipov A, di Salle E, Polli A, Massimini G (2000) Activity of exemestane in metastatic breast cancer after failure of nonsteroidal aromatase inhibitors: a phase II trial. J Clin Oncol 18(11):2234-2244. https://doi.org/10.1200/JCO.2000.18.11.2234

11. Van Asten K, Neven P, Lintermans A, Wildiers H, Paridaens R (2014) Aromatase inhibitors in the breast cancer clinic: focus on exemestane. Endocr Relat Cancer 21(1):R31-49. https://doi.org/ 10.1530/ERC-13-0269

12. Steele N, Zekri J, Coleman R, Leonard R, Dunn K, Bowman A, Manifold I, Kunkler I, Purohit O, Cameron D (2006) Exemestane in metastatic breast cancer: effective therapy after third-generation 
non-steroidal aromatase inhibitor failure. Breast 15(3):430-436. https://doi.org/10.1016/j.breast.2005.08.032

13. Gennatas C, Michalaki V, Carvounis E, Psychogios J, Poulakaki N, Katsiamis G, Voros D, Kouloulias V, Mouratidou D, Tsavaris N (2006) Third-line hormonal treatment with exemestane in postmenopausal patients with advanced breast cancer progressing on letrozole or anastrozole. A phase II trial conducted by the Hellenic Group of Oncology (HELGO). Tumori 92(1):13-17

14. Bertelli G, Garrone O, Merlano M, Occelli M, Bertolotti L, Castiglione F, Pepi F, Fusco O, Del Mastro L, Leonard RC (2005) Sequential treatment with exemestane and non-steroidal aromatase inhibitors in advanced breast cancer. Oncology 69(6):471-477. https://doi.org/10.1159/000090985

15. Chin YS, Beresford MJ, Ravichandran D, Makris A (2007) Exemestane after non-steroidal aromatase inhibitors for post-menopausal women with advanced breast cancer. Breast 16(4):436439. https://doi.org/10.1016/j.breast.2007.02.002

16. Carlini P, Michelotti A, Ferretti G, Ricci S, Giannarelli D, Pellegrini M, Cresti N, Di Cosimo S, Bria E, Papaldo P, Fabi A, Ruggeri EM, Milella M, Alimonti A, Salesi N, Cognetti F (2007) Clinical evaluation of the use of exemestane as further hormonal therapy after nonsteroidal aromatase inhibitors in postmenopausal metastatic breast cancer patients. Cancer Invest 25(2):102-105. https://doi.org/10.1080/07357900701224789

17. Geisler J (2011) Differences between the non-steroidal aromatase inhibitors anastrozole and letrozole-of clinical importance? Br J Cancer 104(7):1059-1066. https://doi.org/10.1038/bjc.2011.58

18. Freedman OC, Amir E, Hanna W, Kahn H, O’Malley F, Dranitsaris G, Cole DE, Verma S, Folkerd E, Dowsett M, Clemons M (2010) A randomized trial exploring the biomarker effects of neoadjuvant sequential treatment with exemestane and anastrozole in post-menopausal women with hormone receptor-positive breast cancer. Breast Cancer Res Treat 119(1):155-161. https://doi.org/ 10.1007/s10549-009-0523-x

19. Lonning PE (2009) Lack of complete cross-resistance between different aromatase inhibitors; a real finding in search for an explanation? Eur J Cancer 45(4):527-535. https://doi.org/10.1016/j.ejca. 2008.10.019

20. Bahrami N, Sauer T, Engebretsen S, Aljabri B, Bemanian V, Lindstrom J, Luders T, Kristensen V, Lorentzen A, Loeng M, Odegard HP, Kvaloy JO, Vestol IB, Geisler SB, Gravdehaug B, Gundersen JM, Geisler J (2019) The NEOLETEXE trial: a neoadjuvant cross-over study exploring the lack of cross resistance between aromatase inhibitors. Future Oncol 15(32):3675-3682. https://doi.org/10.2217/fon-2019-0258

21. Howe LR, Subbaramaiah K, Hudis CA, Dannenberg AJ (2013) Molecular pathways: adipose inflammation as a mediator of obesity-associated cancer. Clin Cancer Res 19(22):6074-6083. https://doi.org/10.1158/1078-0432.CCR-12-2603

22. Iyengar NM, Brown KA, Zhou XK, Gucalp A, Subbaramaiah K, Giri DD, Zahid H, Bhardwaj P, Wendel NK, Falcone DJ, Wang H, Williams S, Pollak M, Morrow M, Hudis CA, Dannenberg AJ (2017) Metabolic obesity, adipose inflammation and elevated breast aromatase in women with normal body mass index. Cancer Prev Res (Phila) 10(4):235-243. https://doi.org/10.1158/19406207.CAPR-16-0314

23. Cirillo D, Rachiglio AM, la Montagna R, Giordano A, Normanno $\mathrm{N}$ (2008) Leptin signaling in breast cancer: an overview. J Cell Biochem 105(4):956-964. https://doi.org/10.1002/jcb.21911

24. Halaas JL, Gajiwala KS, Maffei M, Cohen SL, Chait BT, Rabinowitz D, Lallone RL, Burley SK, Friedman JM (1995) Weightreducing effects of the plasma protein encoded by the obese gene. Science 269(5223):543-546. https://doi.org/10.1126/science. 7624777

25. Pelleymounter MA, Cullen MJ, Baker MB, Hecht R, Winters D, Boone T, Collins F (1995) Effects of the obese gene product on body weight regulation in ob/ob mice. Science 269(5223):540 543. https://doi.org/10.1126/science.7624776

26. Campfield LA, Smith FJ, Guisez Y, Devos R, Burn P (1995) Recombinant mouse OB protein: evidence for a peripheral signal linking adiposity and central neural networks. Science 269(5223):546-549. https://doi.org/10.1126/science.7624778

27. Catalano S, Marsico S, Giordano C, Mauro L, Rizza P, Panno ML, Ando S (2003) Leptin enhances, via AP-1, expression of aromatase in the MCF-7 cell line. J Biol Chem 278(31):2866828676. https://doi.org/10.1074/jbc.M301695200

28. Tessitore L, Vizio B, Pesola D, Cecchini F, Mussa A, Argiles JM, Benedetto C (2004) Adipocyte expression and circulating levels of leptin increase in both gynaecological and breast cancer patients. Int J Oncol 24(6):1529-1535

29. Paolisso G, Rizzo MR, Mone CM, Tagliamonte MR, Gambardella A, Riondino M, Carella C, Varricchio M, D’Onofrio F (1998) Plasma sex hormones are significantly associated with plasma leptin concentration in healthy subjects. Clin Endocrinol (Oxf) 48(3):291-297. https://doi.org/10.1046/j.1365-2265.1998.00383.x

30. Tessitore L, Vizio B, Jenkins O, De Stefano I, Ritossa C, Argiles JM, Benedetto C, Mussa A (2000) Leptin expression in colorectal and breast cancer patients. Int J Mol Med 5(4):421-426. https:// doi.org/10.3892/ijmm.5.4.421

31. Geisler J, Haynes B, Ekse D, Dowsett M, Lonning PE (2007) Total body aromatization in postmenopausal breast cancer patients is strongly correlated to plasma leptin levels. J Steroid Biochem Mol Biol 104(1-2):27-34. https://doi.org/10.1016/j.jsbmb.2006. 09.040

32. Iaffaioli RV, Formato R, Tortoriello A, Del Prete S, Caraglia M, Pappagallo G, Pisano A, Gebbia V, Fanelli F, Ianniello G, Cigolari S, Pizza C, Marano O, Pezzella G, Pedicini T, Febbraro A, Incoronato P, Manzione L, Ferrari E, Marzano N, Quattrin S, Pisconti S, Nasti G, Giotta G, Colucci G, Southern Italy Oncology G (2005) Phase II study of sequential hormonal therapy with anastrozole/ exemestane in advanced and metastatic breast cancer. Br J Cancer 92(9):1621-1625. https://doi.org/10.1038/sj.bjc.6602579

33. Newman G, Gonzalez-Perez RR (2014) Leptin-cytokine crosstalk in breast cancer. Mol Cell Endocrinol 382(1):570-582. https://doi. org/10.1016/j.mce.2013.03.025

34. Shimizu H, Shimomura Y, Nakanishi Y, Futawatari T, Ohtani K, Sato N, Mori M (1997) Estrogen increases in vivo leptin production in rats and human subjects. J Endocrinol 154(2):285-292. https://doi.org/10.1677/joe.0.1540285

35. Luukkaa V, Pesonen U, Huhtaniemi I, Lehtonen A, Tilvis R, Tuomilehto J, Koulu M, Huupponen R (1998) Inverse correlation between serum testosterone and leptin in men. J Clin Endocrinol Metab 83(9):3243-3246. https://doi.org/10.1210/jcem.83.9.5134

36. Machinal F, Dieudonne MN, Leneveu MC, Pecquery R, Giudicelli Y (1999) In vivo and in vitro ob gene expression and leptin secretion in rat adipocytes: evidence for a regional specific regulation by sex steroid hormones. Endocrinology 140(4):1567-1574. https://doi.org/10.1210/endo.140.4.6617

37. Machinal-Quelin F, Dieudonne MN, Pecquery R, Leneveu MC, Giudicelli Y (2002) Direct in vitro effects of androgens and estrogens on ob gene expression and leptin secretion in human adipose tissue. Endocrine 18(2):179-184. https://doi.org/10.1385/ENDO: $18: 2: 179$

38. Wabitsch M, Blum WF, Muche R, Braun M, Hube F, Rascher W, Heinze E, Teller W, Hauner H (1997) Contribution of androgens to the gender difference in leptin production in obese children and adolescents. J Clin Invest 100(4):808-813. https://doi.org/10. 1172/JCI119595

39. Ariazi EA, Leitao A, Oprea TI, Chen B, Louis T, Bertucci AM, Sharma CG, Gill SD, Kim HR, Shupp HA, Pyle JR, Madrack A, Donato AL, Cheng D, Paige JR, Jordan VC (2007) Exemestane's 17-hydroxylated metabolite exerts biological effects as an 
androgen. Mol Cancer Ther 6(11):2817-2827. https://doi.org/10. 1158/1535-7163.MCT-07-0312

40. Hong Y, Yu B, Sherman M, Yuan YC, Zhou D, Chen S (2007) Molecular basis for the aromatization reaction and exemestanemediated irreversible inhibition of human aromatase. Mol Endocrinol 21(2):401-414. https://doi.org/10.1210/me.2006-0281

41. Catalano S, Mauro L, Marsico S, Giordano C, Rizza P, Rago V, Montanaro D, Maggiolini M, Panno ML, Ando S (2004) Leptin induces, via ERK1/ERK2 signal, functional activation of estrogen receptor alpha in MCF-7 cells. J Biol Chem 279(19):1990819915. https://doi.org/10.1074/jbc.M313191200

42. Ollberding NJ, Kim Y, Shvetsov YB, Wilkens LR, Franke AA, Cooney RV, Maskarinec G, Hernandez BY, Henderson BE, Le Marchand L, Kolonel LN, Goodman MT (2013) Prediagnostic leptin, adiponectin, C-reactive protein, and the risk of postmenopausal breast cancer. Cancer Prev Res (Phila) 6(3):188-195. https://doi.org/10.1158/1940-6207.CAPR-12-0374

43. Jarde T, Perrier S, Vasson MP, Caldefie-Chezet F (2011) Molecular mechanisms of leptin and adiponectin in breast cancer. Eur $\mathbf{J}$ Cancer 47(1):33-43. https://doi.org/10.1016/j.ejca.2010.09.005

44. Bodmer JL, Schneider P, Tschopp J (2002) The molecular architecture of the TNF superfamily. Trends Biochem Sci 27(1):19-26. https://doi.org/10.1016/s0968-0004(01)01995-8

45. Mackay F, Ambrose C (2003) The TNF family members BAFF and APRIL: the growing complexity. Cytokine Growth Factor Rev 14(3-4):311-324. https://doi.org/10.1016/s1359-6101(03) 00023-6

46. Pelekanou V, Kampa M, Kafousi M, Darivianaki K, Sanidas E, Tsiftsis DD, Stathopoulos EN, Tsapis A, Castanas E (2008) Expression of TNF-superfamily members BAFF and APRIL in breast cancer: immunohistochemical study in 52 invasive ductal breast carcinomas. BMC Cancer 8:76. https://doi.org/10.1186/ 1471-2407-8-76

47. Chang C, Magracheva E, Kozlov S, Fong S, Tobin G, Kotenko S, Wlodawer A, Zdanov A (2003) Crystal structure of interleukin-19 defines a new subfamily of helical cytokines. J Biol Chem 278(5):3308-3313. https://doi.org/10.1074/jbc.M208602200

48. Gallagher $\mathrm{G}$ (2010) Interleukin-19: multiple roles in immune regulation and disease. Cytokine Growth Factor Rev 21(5):345-352. https://doi.org/10.1016/j.cytogfr.2010.08.005
49. Chen YY, Li CF, Yeh CH, Chang MS, Hsing CH (2013) Interleukin-19 in breast cancer. Clin Dev Immunol 2013:294320. https:// doi.org/10.1155/2013/294320

50. Hsing $\mathrm{CH}$, Cheng $\mathrm{HC}$, Hsu $\mathrm{YH}$, Chan $\mathrm{CH}$, Yeh $\mathrm{CH}$, Li CF, Chang MS (2012) Upregulated IL-19 in breast cancer promotes tumor progression and affects clinical outcome. Clin Cancer Res 18(3):713-725. https://doi.org/10.1158/1078-0432.CCR-11-1532

51. Bagnoli F, Oliveira VM, Silva MA, Taromaru GC, Rinaldi JF, Aoki T (2010) The interaction between aromatase, metalloproteinase 2,9 and CD44 in breast cancer. Rev Assoc Med Bras (1992) 56(4):472-477. https://doi.org/10.1590/s0104-423020100004000 23

52. Martins LM, de Melo Escorcio Dourado CS, Campos-Verdes LM, Sampaio FA, Revoredo CMS, Costa-Silva DR, da Conceicao Barros-Oliveira M, de JesusNery E, do Rego-Medeiros LM, Gebrim LH, Alves-Ribeiro FA, Rodrigues GP, Chagas DC, do Nascimento Marreiro D, da Silva BB (2019) Expression of matrix metalloproteinase 2 and 9 in breast cancer and breast fibroadenoma: a randomized, double-blind study. Oncotarget 10(64):6879-6884. https://doi.org/10.18632/oncotarget.27347

53. Pelekanou V, Villarroel-Espindola F, Schalper KA, Pusztai L, Rimm DL (2018) CD68, CD163, and matrix metalloproteinase 9 (MMP-9) co-localization in breast tumor microenvironment predicts survival differently in ER-positive and -negative cancers. Breast Cancer Res 20(1):154. https://doi.org/10.1186/ s13058-018-1076-X

54. Tauro M, Lynch CC (2018) Cutting to the chase: how matrix metalloproteinase- 2 activity controls breast-cancer-to-bone metastasis. Cancers (Basel). https://doi.org/10.3390/cancers10060185

55. Mitropoulou TN, Tzanakakis GN, Kletsas D, Kalofonos HP, Karamanos NK (2003) Letrozole as a potent inhibitor of cell proliferation and expression of metalloproteinases (MMP-2 and MMP-9) by human epithelial breast cancer cells. Int J Cancer 104(2):155-160. https://doi.org/10.1002/ijc.10941

Publisher's Note Springer Nature remains neutral with regard to jurisdictional claims in published maps and institutional affiliations. 